\title{
REPETIÇÃO DO INDÉBITO TRIBUTÁRIO E O ART. 166 DO CÓDIGO TRIBUTÁRIO NACIONAL
}

\author{
Eduardo Domingos Bottallo \\ Professor Assistente do Departamento de Filosofia e \\ Teoria Geral do Direito da Faculdade de Direito da \\ Universidade de São Paulo
}

\begin{abstract}
Resumo:
O trabalho versa sobre o art. 166 do Código Tributário Nacional (CTN), que impõe condições especiais para a restituição dos denominados tributos indiretos. Para tanto, analisa, de início, a classificação dos tributos em diretos e indiretos, segundo o critério da repercussão econômica. A seguir, critica os enunciados ns. 71 e 546 das súmulas do Supremo Tribunal Federal que, antes do advento do CTN, cuidaram do tema. Mostra o tratamento que este assunto recebeu durante os trabalhos de elaboração do Código e, finalmente, oferece fundamentos para a interpretação do dispositivo, visando prevenir sua utilização como indevido óbice ao direito de repetição do indébito tributário.
\end{abstract}

\begin{abstract}
:
This analysis deals with article 166 of the National Tax Code which imposes special requirements for the repetition of the so-called indirect taxes. For that purpose it analyzes initially the classification of direct and indirect taxes under the criteria of the financial impact. Next, it criticizes holdings ns. 71 and 546 of the Federal Supreme Court which dealt with that subject prior to the enactment of the Tax Cod. The analysis shows further how that subject was considered at the time of the drafting of the Code, and, lastly, presents arguments for the interpretation of article 166 with a view of preventing that it be used as an impediment to the right of restitution of taxes which payment was not due.
\end{abstract}

Unitermos: tributos diretos e indiretos; indébito tributário.

Sumário:

1. Introdução. 2. A classificação dos tributos em diretos e indiretos, segundo o critério da repercussão econômica. 3. As súmulas ns. 71 e 546 do Supremo Tribunal Federal. 4. Fundamentos para interpretação do art. 166 do Código Tributário Nacional. 5. Conclusão. 


\section{Introdução}

O direito à restituição do tributo pago indevidamente tem fundamento nos seguintes princípios constitucionais: a. o da legalidade estrita da tributação (art. $150, \mathrm{I})$; b. o que consagra o direito da propriedade (art. $5^{\circ}$ : XXII); c. o que proíbe a utilização do tributo com efeito de confisco (art. 150, IV); d. o da capacidade contributiva (art. 145, $\S 1^{\circ}$ ).

Nestas condições, os dispositivos do Código Tributário Nacional que tratam do tema (arts. 165 e seguintes) devem ser interpretados segundo os parâmetros emergentes dos preceitos maiores aqui apontados, posto estarem a seu serviço.

Isto significa que, tendo o contribuinte pago tributo que não era devido, ou maior do que o devido, emerge seu direito à repetição que, dadas suas nobres raízes, não pode ser amesquinhado quer pela lei, quer - com muito mais força - por decorrência de interpretação que a ela venha a ser dada.

É dentro deste contexto que se coloca a questão pertinente à restituição dos tributos indiretos.

A concepção que pretende condicionar o reconhecimento do direito de restituição destes tributos à prova de haver o postulante suportado o respectivo encargo, ou de estar seu pleito autorizado por terceiro, que o teria suportado, adquiriu, entre nós, autoridade de Direito Positivo (Código Tributário Nacional, art. 166).

São de alta relevância os problemas ligados a tal determinação, assim como são evidentes os equívocos e injustiças que ela pode ensejar.

Dessa forma, propomo-nos a examinar, no campo doutrinário, a classificação dos tributos em diretos e indiretos, segundo o critério da repercussão econômica; adentrar, a seguir, na apreciação das soluções que o Supremo Tribunal Federal deu ao problema e, finalmente, oferecer os fundamentos para a adequada interpretação do art. 166 do Código Tributário Nacional.

Estes, pois, os objetivos do presente estudo, que, em certa medida, retoma linha de investigação por nós já desenvolvida em outro trabalho. ${ }^{1}$ 
2. A classificação dos tributos em diretos e indiretos, segundo o critério da repercussão econômica.

A classificação dos tributos em diretos e indiretos é tradicional na doutrina.

Alguns autores procuraram estabelecê-la em função de padrões rigorosamente jurídicos, valendo, a propósito, lembrar as posições, substancialmente harmônicas, de Rubens Gomes de Souza e Geraldo Ataliba, o primeiro erigindo a distinção à luz da natureza permanente (tributos diretos) ou temporária (tributos indiretos) do respectivo fato gerador ${ }^{2}$ e o segundo, com apoio em A. D. Giannini, fixando o fator distintivo entre uma e outra espécie em determinadas peculiaridades do elemento material das respectivas hipóteses de incidência. Nessa ordem de idéias, os tributos diretos se caracterizariam por gravarem manifestações imediatas e diretas da capacidade contributiva (patrimônio, renda) e, os indiretos, manifestações mediatas e indiretas dessa mesma capacidade, como o consumo, a prestação de serviços, etc. ${ }^{3}$

São classificações de inegável valor didático, especialmente porque propiciam melhor compreensão de importantes conceitos de Direito Tributário.

Todavia, para os efeitos aqui perseguidos, devemos nos fixar, com maiores detalhes, na análise daquela que procura distinguir os tributos em diretos ou indiretos conforme ocorra, ou-não, em relação aos mesmos, o chamado fenômeno da repercussão econômica.

Lembra Alfredo Augusto Becker, quanto a esse tipo de classificação, que "alguns dos precursores da economia e das finanças públicas já utilizavam-na e a sua consagração e divulgação deve-se principalmente à obra dos fisiocratas" 4

$E$, na verdade, os fundamentos dessa classificação repousam em noções e princípios que, embora relevantes no campo da Economia e da Ciência das Finanças, são absolutamente estranhos ao Direito Tributário.

Assim, seriam diretos aqueles suportados em definitivo pelo contribuinte, obrigado por lei ao seu pagamento, e indiretos os que são, ou podem

2. Compêndio de Legislação Tributária, Ed. Financeiras, 1952, p. 142.

3. Apontamentos de Ciência das Finanças, Direito Financeiro e Tributário, Ed. Revista dos Tribunais, 1969, p. 92.

4. Teoria Geral do Direito Tributário, São Paulo, Saraiva, 1963, p. 489. 
ser, transferidos por este ("solvens" ou contribuinte "de jure"), através do chamado fenômeno da repercussão econômica, para uma outra pessoa que, por sua vez, os transferirá ou suportará em definitivo (contribuinte "de fato").

O critério da repercussão econômica não conta com respaldo jurídico bastante para determinar a classificação de tributos em diretos e indiretos.

$\mathrm{Na}$ verdade, é inadmissível, neste plano, condicionar-se o reconhecimento do direito de restituição do indébito tributário à prova de haver o contribuinte assumido o respectivo ônus financeiro, ou estar, a tanto, autorizado por terceiros que o assumiu.

Entretanto, embora sua artificialidade venha sendo proclamada, de longa data, pela mais autorizada doutrina, ${ }^{5}$ esta classificação continua a influenciar, poderosamente, administradores públicos, legisladores e magistrados.

É o que veremos, a seguir.

\section{As súmulas ns. 71 e 546 do Supremo Tribunal Federal.}

Anteriormente ao advento do Código Tributário Nacional, a questão da restituição dos tributos indiretos foi objeto de largo tratamento pretoriano, que acabou por consolidar-se nos enunciados ns. 71 e 546 das súmulas do STF

Vejamos, de modo sucinto, como isto se deu.

A jurisprudência, tanto das cortes inferiores como do próprio Supremo Tribunal Federal, partindo de uma posição doutrinariamente correta, como seja, a do acolhimento, pura e simples, da tese de que cabia ao Fisco, que percebesse imposto indevido, a obrigação de restituí-lo (tese, de resto, que encontra respaldo no preceito do art. 964 do Código Civil), foi, por assim dizer, retrocedendo até o ponto de mostrar-se receptiva à influência do fenômeno da repercussão, erigindo-o em poderoso obstáculo às pretensões dos contribuintes de reaver o indevido, ainda quando, sobre essa circunstância, ou seja, a de ser o tributo indevido, não pairasse qualquer dúvida.

Esse movimento regressivo de nossos tribunais teve origem na "pertinaz recusa dos órgãos administrativos de deferirem pedidos de restituição de

5. Cf. Alfredo Augusto Becker, op. e loc. cit., e, ainda, Rubens Gomes de Souza, "Parecer", Revista de Direito Administrativo, v. 10, p. 61; Amilcar de Araújo Falcão, Direito Tributário Brasileiro, Ed. Financeiras, pp. 56-57 e, bem recentemente, Sacha Calmon Navarro Coelho, "Prescrição e Decadência no Direito Tributário", Revista de Direito Tributário, v. 71, pp. 90-91. 
impostos indiretos" 6 a qual, finalmente, acabou por encontrar guarida no Poder Judiciário que, a partir de determinado momento, passou a ceder até diante de argumentos surpreendentes, como a alegação de que, em razão do fenômeno da translação (e da "consequiente" transferência do ônus do imposto ao contribuinte "de fato"), reconhecer-se o direito de repetição ao "solvens" implicaria propiciar-lhe enriquecimento ilícito, sendo, neste caso, preferível que o beneficiário do locupletamento fosse o Estado, pois ele, ao menos, representa o interesse coletivo. ${ }^{7}$

Com o advento das "súmulas" do STF, assim dispôs o seu enunciado n. 71:

\section{"embora pago indevidamente, não cabe restituição de tributo indireto"}

Os precedentes que deram origem a este verbete assentaram-se em argumentos inferidos a partir da pretendida repercussão econômica dos tributos indiretos, da qual decorreria: a. a inocorrência de prejuízo financeiro do "solvens" pelo recolhimento do tributo indevido, o que lhe inibiria o uso da ação de repetição, pois esta, fundada na eqüidade, não pode servir de instrumento para enriquecimento sem causa; b. a conseqüente falta de legitimidade do "solvens" para pleitear a repetição; c. a inexistência de obrigação do "accipiens" de restituir o indevido a quem não provou haver sofrido desfalque patrimonial; d. a consideração - já destacada - de que, entre propiciar-se enriquecimento sem causa ao particular ou ao Estado, é preferível que se opte por esta última alternativa, já que tal enriquecimento reverteria em benefício da coletividade, da qual é o Estado o representante.

É bem de ver que tais argumentos, embora apresentados sob coloração jurídica, pouco ou quase nada guardam dessa característica.

Fica evidente que pesaram fatores de caráter econômico, político, e até emocional para a consolidação da jurisprudência - base do enunciado em exame -, que somente pode ser explicada à luz das condições sociais e dos graves distúrbios financeiros que imperavam no País no início da década de 60 .

6. Gilberto de Ulhoa Canto, "Natureza Tributária de Taxa de Despacho Aduaneiro", Revista de Direito Público, v. 1, p. 100.

7. Do voto vencedor do min. Oscar Saraiva na apreciação do R.E. 38.508, apud Gilberto de Ulhoa Canto, op. e loc: cit. 
Não-bastasse o fato de calcar-se em fundamentos insólitos, tal enunciado padecia ainda de outro defeito bastante marcante, qual seja, sua redação, lacônica e pouco esclarecedora, reduzindo, como num passe de mágica, toda problemática que envolve a restituição do indébito tributário a termos tão-singelos que, por certo, à sua sombra, muitas injustiças e injuridicidades foram cometidas.

Mais tarde, descolorida atenuação ao rigor deste enunciado foi exteriorizada com o advento do de n. 546:

"Cabe a restituição do tributo pago indevidamente, quando reconhecido, por decisão, que o contribuinte 'de jure' não recuperou do contribuinte de fato o quantum respectivo"

Os fundamentos jurisprudenciais deste verbete demonstram que, sem pretender revogar o de n. 71, objetivou, quando muito, avivar a lembrança de que o critério de classificação dos tributos segundo a repercussão econômica não é infalível e, portanto, sua invocação para solucionar o problema da repetição do indébito tributário não pode ser indiscriminada, dependendo das condições peculiares de cada caso concreto.

O enunciado n. 546, portanto, apenas amenizou a inflexibilidade da jurisprudência que o precedeu, sem, entretanto, afastá-la, como seria desejável. ${ }^{8}$

4. Fundamentos para uma interpretação do art. 166 do Código Tributário Nacional.

Dispõe o art. 166 do CTN:

"Art. 166. A restituição de tributos que comportem, por sua natureza, transferência do respectivo encargo financeiro somente será feita a quem prove haver assumido o referido encargo ou, no caso de tê-lo

8. A análise dos precedentes que deram origem aos enunciados 71 e 546 foi feita em nosso "Restituição...' cit., pp. 320-329. 
transferido a terceiro, estar por este expressamente autorizado a recebê-la"

Desde logo podemos afirmar, com base nas observações já feitas e nas conclusões delas extraídas, que, sob o ponto de vista científico, o dispositivo em causa é inteiramente desprovido de méritos.

E como se isso não fosse suficiente, ressente-se, ainda, dos defeitos de uma redação menos feliz, que o torna particularmente obscuro e indefinido.

Todavia, ele existe e como tal deve ser reconhecido, dada sua "validade universal no nosso Direito" (Geraldo Ataliba).

Resta, pois, ao intérprete, tentar superar essas dificuldades e penetrar no espírito da norma, com vistas ao estabelecimento de bases racionais para sua aplicação, pois:

"Somente o conhecimento do espírito que anima a lei permite superar as dificuldades decorrentes da imperfeita formulação da norma, corrigir as contradições decorrentes de oposições verbais entre diferentes preceitos jurídicos e vencer as incertezas que surgem sempre que seja necessário trazer os fenômenos da vida prática, sempre diferentes e variáveis, para debaixo do império de uma norma cuja formulação permanece inalterada" 9

Longe de nós a pretensão de esgotar o trabalho de exegese do dispositivo em causa; desejamos apenas registrar algumas observações que nos parecem de relevância para a adequada fixação do seu campo de aplicação.

O anteprojeto do Código Tributário Nacional de autoria de Rubens Gomes de Souza (DOU, Seção I, de 25.8.1953, pp. 14.567 a 14.593) tratava da questão atinente à repetição do indébito em seus arts. 201 a 204, sem estabelecer, para o exercício desse direito, quaisquer condições do tipo das previstas no preceito sob exame.

9. Ezio Vanoni, Natureza e Interpretação da Lei Tributária, Ed. Financeiras, 1964, p. 134. 
Vale dizer, o anteprojeto, adotando a única posição doutrinariamente adequada à espécie, simplesmente desconheceu a existência dos tributos chamados indiretos, atribuindo, incondicionalmente, ao "solvens" o direito de repetição, à vista da ocorrência concreta das hipóteses previstas de pagamento indevido.

Já o projeto revisto por uma Comissão designada pelo Ministério da Fazenda (Diário do Congresso Nacional, Seção I, de 27.3.1963, pp. 889 a 911) apresentava disposição paralela àquela que, afinal, foi consagrada, ao preceituar, em seu art. 131:

"Existindo disposição legal expressa que determine ou faculte ao contribuinte a transferência do tributo a terceiro, o direito referido no artigo anterior fica subordinado à prova de que a transferência não ocorreu, por impossibilidade material ou jurídica em face das circunstâncias materiais do caso.

Parágrafo único. O terceiro que faça prova de lhe haver sido transferido o tributo pelo contribuinte nos termos deste artigo, sub-roga-se no direito daquele à respectiva restituição".

Embora em certos aspectos também equívoco, este texto apresentava, sobre o que se converteu no art. 166 do Código, a vantagem de indicar, de forma mais clara, os tributos cuja restituição estaria condicionada à prova de assunção do ônus pelo "solvens"

Assim, ao invés de referir-se, imprecisamente, a tributos que "por sua natureza" comportem a transferência do ônus, o projeto falava em tributos que, por "determinação legal expressa", podem ou devem ser transferidos, situação, como se percebe, de compreensão muito mais imediata.

Nisto assenta nossa convicção de que a correta interpretação do art. 166 somente pode ser erigida com observância da diretriz apontada pelo art. 131 do projeto.

Em outras palavras, temos que o art. 166 diz respeito exclusivamente à restituição daqueles tributos cuja lei outorga ao contribuinte "de jure" o direito de 
receber de determinada pessoa o reembolso do montante por ele pago, ou de reter, de valor eventualmente devido a terceiro, o montante do tributo a pagar.

Esta configuração do problema é essencial para dar ao preceito legal sob exame condições para sua apropriada aplicação.

Tomemos o exemplo do IPI.

A lei de regência desse tributo dá ao fabricante (contribuinte "de jure") o direito de, no ato da venda de seu produto, acrescer, ao valor da operação, aquele correspondente ao reembolso do montante a recolher aos cofres públicos, a título de imposto.

Nesta hipótese, ocorre o nascimento de duas relações jurídicas: uma entre o sujeito passivo da obrigação tributária (contribuinte "de jure") e o sujeito ativo dessa mesma obrigação, ou seja, o Poder Tributante; a segunda, entre o contribuinte "de jure" (que já aqui assume a posição de sujeito ativo) e o contribuinte "de fato" (o adquirente de seu produto), que se torna o sujeito passivo de um direito de crédito, tendo por fundamento a primeira relação. ${ }^{10}$

À luz desse exemplo, pode-se fixar o sentido que comporta o mencionado art. 166: a "legitimatio ad causam" do contribuinte "de jure" para pedir a restituição do tributo, quando indevidamente pago, somente existirá na medida em que este provar haver assumido seu encargo (o que seria uma situação de exceção dentro da sistemática do IPI), ou então - e esta é a regra - estar autorizado a fazê-lo pelo contribuinte "de fato" determinado, sobre o qual o ônus repercutiu por força da relação de direito criada.

Nestas condições, o dispositivo em estudo tem seu alcance limitado aos casos de restituição dos tributos em relação aos quais o fenômeno da translação, por expressa determinação legal, e só por isso, passou a ser considerado como fato jurídico.

São, na verdade, aqueles tributos que, em razão do regime legal a que estão sujeitos, o mesmo Becker considera sujeitos a um processo de "repercussão jurídica" que não se confunde nem guarda relação necessária com a chamada repercussão econômica, pois esta "pode ocorrer apenas parcialmente ou até não se realizar, embora no plano jurídico se tenha efetivado" 11

10. Cf. Alfredo Augusto Becker, op. cit., p. 488.

11. Op. cit., p. 487. 
Dois seriam, ainda no entender de Becker, os sistemas de repercussão jurídica do tributo: por reembolso e por retenção na fonte, e o saudoso autor gaúcho assinala a distinção entre ambos:

"No reembolso, há o acréscimo do direito de crédito do tributo ao crédito que o contribuinte 'de jure' possui com relação a uma outra pessoa, em razão de um determinado negócio jurídico. Na retenção na fonte, há redução num débito que o contribuinte 'de jure' tem perante uma determinada pessoa, em virtude de um determinado negócio jurídico" ${ }^{12}$

Tanto em uma quanto em outra espécie, contudo, a transferência do ônus se opera por força de lei e essa característica, na verdade, é que deve ser levada em conta para o estabelecimento das bases para a correta aplicação do preceito constante no art. 166 do Código.

O vínculo entre os contribuintes "de jure" e de "de fato" pelo qual o fenômeno da translação, legalmente reconhecido, se opera, é de natureza privada, da mesma forma que o chamado contribuinte "de fato" é estranho à relação jurídica tributária.

Todavia, o art. 166 atribuiu, para seus efeitos, relevância a tal vínculo e a tal figura, de sorte que somente quando a lei de regência de um tributo reconhece ao contribuinte "de jure" $o$ direito de transferir ou descontar seu valor (determinado) a ou de um terceiro, também determinado, é que ele, contribuinte "de jure", poderá ter condições materiais necessárias para, em caso de restituição, cumprir os requisitos ali estabelecidos.

A exigência legal de determinação do valor a ser transferido ou descontado, bem como da pessoa a quem o mesmo será transferido, ou de quem será descontado, é condição essencial para a incidência do dispositivo.

Estas serão, então, as espécies tributárias que "por sua natureza" (natureza legal) comportam a transferência do ônus.

12. Op. cit., p. 488. 
Admitir-se um campo de aplicação mais amplo para o preceito em consideração, ao ponto de seu cumprimento condicionar a restituição de outras espécies, sujeitas a regime jurídico diverso, seria, na prática, o mesmo que se afirmar a impossibilidade de sua repetição.

Nem se diga que o contribuinte poderia demonstrar, por seus livros e arquivos, que não agregou o tributo ao preço, ou, se o agregou, que está autorizado pelo contribuinte dito "de fato" a receber a restituição.

Isto ocorrerá apenas se o regime legal aplicável ao tributo exigir a manutenção de assentamentos que ensejem a identificação do valor do imposto transferido ou descontado e da pessoa a quem ou de quem o foi. Em outras palavras, isso poderá ocorrer com relação aos tributos que, também em nosso entender, estão sujeitos à regra do art. 166.

Todavia, quanto aos demais tributos, ainda que sob critérios econômicos possam ser taxados de "indiretos" essa demonstração será praticamente impossível.

Como poderia, por exemplo, uma empresa, contribuinte do imposto de importação, ou das contribuições patronais destinadas ao custeio da Previdência Social, saber quem arcou, e em que proporções, com o ônus destes tributos que teve de pagar para desenvolver suas atividades comerciais, industriais ou de prestação de serviços? Quais seriam os registros ou assentamentos onde essas evidências estariam indicadas, com a precisão e o detalhamento necessário, se não há obrigação legal de fazê-lo? Por certo em nenhum.

Por aí se vê que, em hipóteses como as aventadas, a invocação do art. 166 do Código Tributário Nacional, para condicionar a restituição do indevido, implica proclamar-se a própria impossibilidade dessa restituição, o que repugna a consciência jurídica, pois não se pode admitir que uma lei opere no sentido de impedir que sejam alcançados os propósitos que ela própria se destina a assegurar, máxime quando se tem em mente - como a princípio, apontado - que esta lei não é mais do que veículo destinado à implementação, dentro do tema que nos ocupa, dos importantes e fundamentais princípios constitucionais da legalidade, da garantia da propriedade e da capacidade contributiva. 
5. Conclusão.

Como arremate de nosso trabalho, podemos assentar que, fundamentalmente, a aplicação do art. 166 do CTN estará sempre na dependência do regime legal a que, in specie, o tributo a restituir estiver sujeito: se este (regime legal) contemplar uma das modalidades de "repercussão jurídica" acima indicadas, haverá campo para aplicação do dispositivo em pauta; caso contrário, não poderá o mesmo ser invocado.

Tributos, embora rotulados de "indiretos" por outros padrões, mas cujo regime legal não seja de molde a ensejar a criação de relações jurídicas que, especificamente, autorizem o contribuinte "de jure" a transferir seu ônus financeiro a terceiro, não podem ter sua restituição condicionada à regra do art. 166 do Código Tributário Nacional.

São Paulo, janeiro de 1999. 